\title{
Do resting brain dynamics predict oddball evoked-potential?
}

Tien-Wen Lee ${ }^{1,2}$, Younger W-Y Y $u^{3}$, Hung-Chi Wu ${ }^{4}$ and Tai-Jui Chen ${ }^{5,6^{*}}$

\begin{abstract}
Background: The oddball paradigm is widely applied to the investigation of cognitive function in neuroscience and in neuropsychiatry. Whether cortical oscillation in the resting state can predict the elicited oddball eventrelated potential (ERP) is still not clear. This study explored the relationship between resting electroencephalography (EEG) and oddball ERPs. The regional powers of 18 electrodes across delta, theta, alpha and beta frequencies were correlated with the amplitude and latency of N1, P2, N2 and P3 components of oddball ERPs. A multivariate analysis based on partial least squares (PLS) was applied to further examine the spatial pattern revealed by multiple correlations.

Results: Higher synchronization in the resting state, especially at the alpha spectrum, is associated with higher neural responsiveness and faster neural propagation, as indicated by the higher amplitude change of N1/N2 and shorter latency of P2. None of the resting quantitative EEG indices predict P3 latency and amplitude. The PLS analysis confirms that the resting cortical dynamics which explains N1/N2 amplitude and P2 latency does not show regional specificity, indicating a global property of the brain.

Conclusions: This study differs from previous approaches by relating dynamics in the resting state to neural responsiveness in the activation state. Our analyses suggest that the neural characteristics carried by resting brain dynamics modulate the earlier/automatic stage of target detection.
\end{abstract}

\section{Background}

The oddball task is a broadly applied paradigm in the investigation of cognitive function. Target stimuli are presented amongst more frequent standard background stimuli. A distracter stimulus may also be used to ensure that the response is to the target rather than to the change from a background pattern. The waveform of elicited evoked-potential is thought to reflect central electrical activity related to a number of cognitive processes, such as attention allocation, stimulus evaluation and memory-based comparison, and has been studied in a variety of neurological and psychiatric disorders [1-9]. Oddball design is welcome because of its conceptual clarity, replicability, stability and inter-laboratory consistency [10-12]. The associated event-related potential (ERP) is composed of several components such as N1, $\mathrm{P} 2, \mathrm{~N} 2$ and $\mathrm{P} 3(00)$, indicating early/pre-attentive to late selective attention and cognitive processing. N1 and N2

\footnotetext{
* Correspondence: tjchen71@kimo.com

${ }^{5}$ Department of Psychiatry, E-DA Hospital, Kaohsiung County, Taiwan

Full list of author information is available at the end of the article
}

are the post-stimulus negative deflections respectively peaking at around $100 \mathrm{~ms}$ and $200-300 \mathrm{~ms}$, while P2 and $\mathrm{P} 3$ are the post-stimulus positive deflections respectively peaking at around $150-200 \mathrm{~ms}$ and $300 \mathrm{~ms}$. Despite broad application, the determinants and moderators of each oddball ERPs component are still not fully understood.

The early (N1 and P2) components of oddball ERPs have been regarded to indicate automatic stimulus processing. They are influenced by early aspects of attention and orientation $[13,14]$. The N2 component may reflect the attended mismatch detection [15], whereas the P3 component is assumed to be an indicator of controlled processing [16]. Further, N2-P3 ERP complex has been reported to differentiate the infrequent targets and the frequent non-targets across different physical attributes of experimental stimuli [17-20]. A variety of psychological and biological factors may modulate the latency and amplitude of oddball ERPs. The psychological modulators comprise arousal, cognitive effort, task difficulty, experimental design, perceived emotion, meditation 
practice and even personality [21-25]. Many pharmacological agents, including ethanol, and genetic factors may also influence the profile of oddball ERPs [23,26-32]. Each component of oddball ERPs may correspond to a distinct psychological sub-process and may possess dissociable paths to interactive psycho-biological variables.

Among the modulators of oddball ERPs, the perspective of neural-neural interaction has been less addressed in the previous literature. Nevertheless, neural-neural interaction is critical in the theoretical framework to explain the generation of ERP. For example, previous studies have proposed that phase-resetting and phase synchronization between different frequency bands play a substantial role in the construction of early ERP $[33,34]$. Barry et al. found that the stimuli onset relative to the phase of brain dynamics may modulate the amplitude of oddball N1, P2 and P3 [35]. Regarding neuralneural interaction, whether the quantitative EEG (qEEG) indices can predict the oddball ERPs manifest over the vertex is still not clear. QEEG, in contrast to clinical EEG, is digital EEG information quantified using various precise and objective ways by computerized analytic and statistical techniques. However, twin studies have demonstrated moderate to high heritability in P300 and resting EEG power spectrum, and significant genetic correlation between P300 and background EEG power $[36,37]$. The observed common genetic influences on P300 amplitude and resting EEG support above conjecture that across-subject variance in resting neural dynamics may explain the variability of P300. Neural synchronization (e.g. regional power) in the resting state has been reported to correlate with performance on several neuro-psychological tasks, and even neuropsychiatric conditions [38-43]. Previous studies have proposed that the neuromatrix in the resting state may predict performance on attention tasks, as well as working memory tasks [44-46]. The agreement between structural (diffusion tensor imaging) and functional connectivity at a resting state has also been examined by crossmodal validation [47-49]. Furthermore, an early report by Romani et al. showed that pre-stimulus slow-wave activity differentiated the N2 latency and P3 amplitude elicited by the oddball paradigm, which supported the potential linkage of neural dynamics between the resting state and the activation state of target detection [50]. This study plans to investigate the relationship between cortical dynamics in resting state and the averaged oddball ERPs (as a surrogate of neural responsivity).

This study extends the previous understanding by incorporating resting brain dynamics into the study of auditory oddball ERPs. The resting neural informatics are actually irrelevant to the occurrence of oddball events, very different from previous approaches addressing brain dynamics at or after the occurrence of stimulus [33-35]. We are particularly interested in the qEEG indices of regional power at the fronto-parietal pathway associated with selective attention and working memory [44-46,51]. To the best of our knowledge, whether brain oscillation in the resting state can predict the oddball ERPs profile has never been assessed before. Since both gender and age may influence P300 topography and neural interaction in the resting state, this preliminary study restricts research sample to young females. The restricted sample may eliminate the potential interaction of gender and the differential impact of age on cortico-electrical activities and oddball ERPs [4,52-57].

\section{Methods}

\section{Subjects}

A total of 233 right-handed healthy young females, aged 19-22, were enrolled. All the participants were evaluated by licensed psychiatrists following a semi-structured interview process. The neurological and physical examinations were performed by licensed medical doctors. Those who had a history of substance abuse, psychiatric disease, or major medical or neurological disorder were excluded. Only those who had been medication-free (including birth control pills) for at least two weeks were enlisted. 218 participants were included in the final analysis. This project was approved by the local ethics committee conforming with Helsinki declaration. Informed consent was obtained from all participants prior to the commencement of the investigation.

\section{EEG recordings and analyses}

All participants received a 3-minute conventional, eyesclosed, awake, digital EEG after a 5-minute habituation to the experimental environment (Brain Atlas III computer, Biologic System Company, Chicago). Recordings were in accord with the international 10-20 system, with linked ear reference, a $128 \mathrm{~Hz}$ sampling rate and impedance below $3 \mathrm{k} \Omega$ [58]. The artifact of vertical eyeball movement was detected from electrodes placed above and below the right eye, with the horizontal analog derived from electrodes placed at the left outer canthus. The common average reference method was adopted. We We defined four frequency bands as follows: delta 1 to $4 \mathrm{~Hz}$, theta 4 to $8 \mathrm{~Hz}$, alpha 8 to $12 \mathrm{~Hz}$ and beta 12 to $24 \mathrm{~Hz}$. EEG segments with artifacts were deleted by an experienced EEG researcher.

An auditory oddball paradigm was used to elicit the oddball event-related potential (ERP). Fifty target tones $(2,000 \mathrm{~Hz}, 80 \mathrm{~dB}$ SPL, probability $15.4 \%)$ and 275 nontarget tones $(1,000 \mathrm{~Hz}, 80 \mathrm{~dB} \mathrm{SPL})$ were interspersed in random order and presented binaurally. The tone pips were delivered at a stimulation rate of 1.3 tones/sec, with a 50 -ms duration for each (10 ms rise/fall times). 
Subjects were required to count target stimuli while ignoring the frequent low-pitched tones. The data was discarded if the reported target number deviated more than 5 from the correct answer. The inter-trial interval of the auditory stimuli was varied in a $1,100-1,500 \mathrm{~ms}$ range (1,300 $\mathrm{ms}$ in average) to avoid expectancy effect. Other oddball ERPs detail can be referred to elsewhere [59].

As to the resting EEG signals, Fast Fourier Transform (FFT) was applied to consecutively non-overlapped and artifact-free segments of $20 \mathrm{sec}$ to derive the mean EEG power for each electrode at a specified frequency band [60] (unit: $\mu \mathrm{V}^{2}$ ). Eighteen electrodes, including F7, F3, Fz, F4, F8, T3, C3, Cz, C4, T4, T5, P3, Pz, P4, T6, O1, $\mathrm{Oz}$ and $\mathrm{O} 2$, were included for further analysis with oddball ERPs.

\section{Statistical analyses}

This study aims at investigating whether the quantitative EEG indices in the resting state predict oddball ERPs parameters. For the oddball waveforms at $\mathrm{Fz}, \mathrm{Cz}$ and $\mathrm{Pz}$, the amplitude and latency of N1, P2, N2 and P3 were quantified. Our preliminary analyses revealed a highly correlated pattern across Fz-oddball, $\mathrm{Cz}$-oddball and Pzoddball. We thus performed principal component analysis (PCA) to reduce the three oddball ERPs to a representative one, PCA-oddball. The amplitude and latency of N1, P2, N2 and P3 from the extracted PCA-oddball were then correlated (Pearson's correlation) with resting state spectral powers. For each test set in this study, the criterion for significance is thresholded at $P<0.05$, twotailed. We assume independence of each frequency band and perform the Bonferroni correction based on $P=1$ $(1-0.05)^{1 / \mathrm{n}}$, where $\mathrm{n}$ equals the number of comparisons. The statistical threshold of the Bonferroni correction is $0.0028(\mathrm{n}=18)$. Given that the electro-cortical activities are not completely independent, we report both $P<0.01$ and $P<0.0028$ in case the multiple comparison correction is too stringent.

For the correlation maps of resting dynamics and PCAoddball showing significance, we used a multivariate method of partial least squares (PLS) to examine the spatial pattern of resting neuro-dynamics that predicted PCA-oddball. The PLS method was developed by McIntosh et al. and has been successfully applied in various neuroimaging studies, including EEG [61-63]. PLS is different from the voxel-wise approach in neuroimaging field that used to adopt multiple univariate statistical analyses. On the contrary, PLS is a multi-variate method to extract the distributed patterns of brain response that are related to task demands (categorical variables, Task PLS) or task performance (continuous variables, Behavioral PLS). In brief, PLS resorts to singular value decomposition (SVD) to compute the relation between 2 (or more) multivariate factors (e.g. from variance-covariance matrix) and yields a new set of covariance images that correspond to the strongest effects in the data. PLS is conceptually similar to canonical correlation analysis but optimizes covariance, not correlation. The outputs of PLS serve as the bases to weight the original multivariate factors to achieve optimization of the SVD factorization. The statistical assessment of PLS relies on non-parametric methods to provide the information of statistical strength and reliability of regional contribution by permutation test and bootstrap resampling, respectively. The variance-covariance matrix, in this study, is derived from oddball ERPs (218 subjects and 4 amplitudes or 4 latencies) and resting EEG (218 subjects and 18 electrodes). We utilized the Behavior PLS module, in contrast to Task PLS counterpart, to assess the saliencies of "behavior" (PCA-oddball) and "brain" (resting qEEG) [62]. The test of significance of PLS analysis is accomplished by permutation and bootstrapping for 2,500 and 500 times, respectively. The ratio of the salience to the bootstrap standard error is approximately equivalent to a z-score [64]. The spatial patterns with the squared singular value less than 10 percent of the total squared sum of all singular values were disregarded.

\section{Results}

The grand mean waveform of oddball ERPs and resting EEG spectrum are illustrated in Figure 1 and 2, respectively. In Figure 1, the negative value of grand mean P2 is due to the relatively large variance in N2 and P2 latencies and hence, the individual $\mathrm{P} 2$ is masked by negative deflections in N1-P2 and P2-N2 segments. For the PCA-oddball, the percentage of the first eigenvalue relative to the summation of all eigenvalues ranges from 0.80 to 0.95 (mean 0.90). The detail of PCA-oddball and the N1, P2, N2, and P3 components of oddball ERPs are summarized in Table 1. The amplitude and latency of

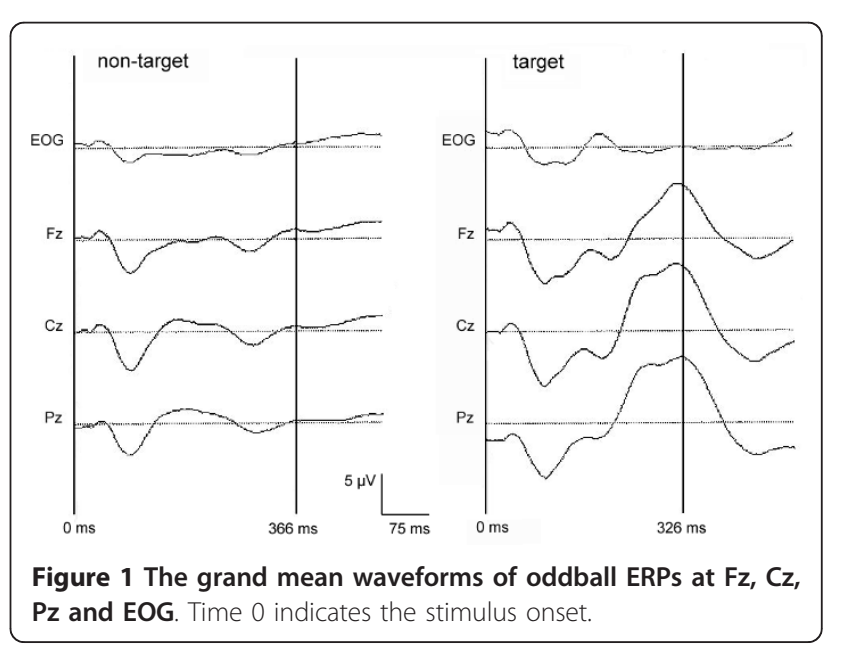




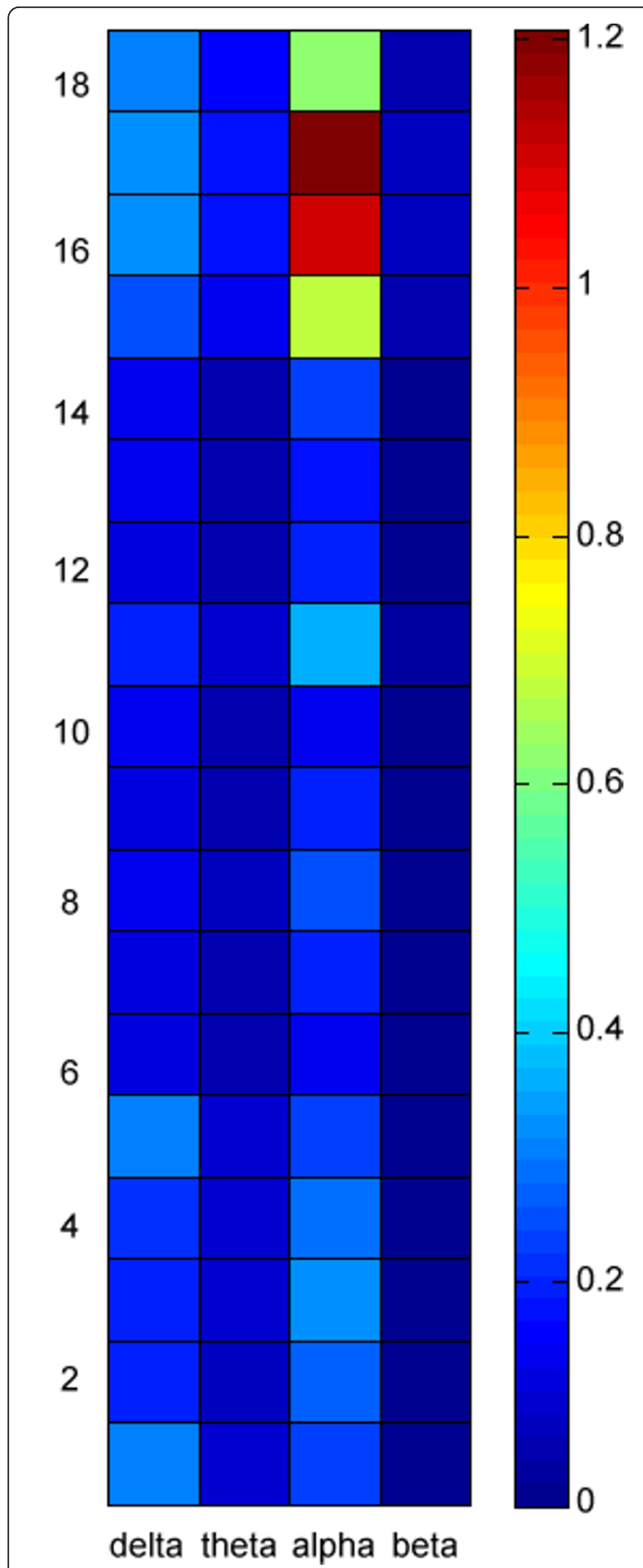

Figure 2 The average mean powers of 18 electrode sites at delta, theta, alpha and beta frequencies of resting EEG. The values are represented by color, with a color-bar at the right side. Ordinate is the EEG electrodes: 1. F7, 2. F3, 3. FZ, 4. F4, 5. F8, 6. T3, 7. C3, 8. Cz, 9. C4, 10. T4, 11. T5, 12. P3, 13. Pz, 14. P4, 15. T6, 16. O1, 17. $\mathrm{Oz}, 18 . \mathrm{O} 2$.
Table 1 The event-related components of the oddball task

\begin{tabular}{lllll}
\hline & Frontal & Central & Parietal & Var (1st Eig) \\
\hline N1 & $-3.42(1.64)$ & $-3.86(1.71)$ & $-3.15(1.50)$ & 0.94 \\
\hline P2 & $1.64(1.37)$ & $2.74(1.70)$ & $2.89(1.64)$ & 0.80 \\
\hline N2 & $-3.67(2.38)$ & $-3.96(2.57)$ & $-2.90(2.09)$ & 0.95 \\
\hline P3 & $6.77(3.12)$ & $8.33(3.83)$ & $8.38(3.67)$ & 0.89 \\
\hline N1 & $95.04(13.96)$ & $94.76(13.32)$ & $93.30(14.57)$ & 0.92 \\
\hline P2 & $179.65(35.59)$ & $178.61(32.39)$ & $178.30(31.73)$ & 0.89 \\
\hline N2 & $211.77(32.48)$ & $207.83(32.34)$ & $207.72(35.11)$ & 0.95 \\
\hline P3 & $324.39(29.46)$ & $320.59(30.30)$ & $321.53(30.57)$ & 0.87 \\
\hline
\end{tabular}

Upper part: amplitude $(\mu \mathrm{V})$, lower part: latency $(\mathrm{ms})$, expressed as Mean (STD) $\operatorname{Var}(1 \mathrm{st}$ Eig): variance explained by first principal component

PCA-oddball are correlated with regional power derived from resting EEG. In the text henceforth, the prefix PCA- before oddball components will be discarded without loss of clarity. We notice aggregated patterns in which the regional power of the resting EEG is significantly correlated with $\mathrm{N} 1$ amplitude, $\mathrm{N} 2$ amplitude and P2 latency. For N1 latency, N2 latency, P2 amplitude and P3 latency/amplitude, the results are generally negative. The details are described below.

$\mathrm{N} 1$ and N2 amplitudes are negatively correlated with regional power at the alpha band. Since we preserve the signs of negative peaks, our finding implies that the stronger the regional power at alpha in resting state, the greater the magnitude of the negative peaks at N1 and N2. The electrodes with significant correlations cover widespread brain regions, including frontal, temporal and parietal areas. The results of N1 and N2 amplitudes with regional power are summarized in Table 2.

The latency of P2 is negatively correlated with the regional power at resting alpha band. This finding implies that stronger regional power at resting alpha would shorten the P2 latency. As in the analyses of N1/N2 amplitudes, most of the electrodes reveal significant correlations, indicating that the relationship is substantiated by a "global" neural characteristic, instead of regional specificity. The statistical threshold of the Bonferroni correction is the same as before, 0.0028 . The results of the correlation of regional powers and P2 latency are displayed in Table 2. As to the details of the N1, P2, N2, P3 results not present in this report, interested readers may refer to the supplementary material (Tables S1 to S2, at http://www. websdj.idv.tw/kiki/rEEG_P300.pdf). The supplementary material also contains the results of multiple regression analysis with oddball ERPs and oscillatory powers as dependent and explanatory variables, respectively (Table S3). 
Table 2 Correlation coefficients of oddball ERP and resting regional power across 18 channels at 4 frequency bands

\begin{tabular}{|c|c|c|c|c|c|c|c|c|c|c|c|c|}
\hline & \multicolumn{4}{|c|}{ N1 Amplitude } & \multicolumn{4}{|c|}{ N2 Amplitude } & \multicolumn{4}{|c|}{ P2 Latency } \\
\hline & delta & theta & alpha & beta & delta & theta & alpha & beta & delta & theta & alpha & beta \\
\hline F7 & -0.049 & -0.124 & $-0.203^{*}$ & -0.122 & -0.127 & -0.121 & -0.180 & -0.116 & -0.110 & -0.124 & -0.184 & -0.099 \\
\hline F3 & -0.104 & -0.186 & -0.176 & -0.132 & -0.110 & -0.109 & -0.162 & -0.127 & -0.139 & -0.173 & -0.183 & -0.112 \\
\hline$\overline{F z}$ & -0.100 & -0.177 & -0.170 & -0.123 & -0.142 & -0.137 & -0.166 & -0.108 & -0.156 & -0.150 & -0.173 & -0.084 \\
\hline $\mathrm{F} 4$ & -0.088 & -0.173 & -0.183 & -0.155 & -0.083 & -0.100 & -0.176 & -0.115 & -0.109 & -0.159 & -0.181 & -0.107 \\
\hline F8 & -0.092 & -0.156 & -0.197 & -0.147 & -0.088 & -0.097 & -0.176 & -0.130 & -0.057 & -0.133 & -0.174 & -0.116 \\
\hline T3 & -0.051 & -0.162 & $-0.206^{*}$ & -0.111 & -0.088 & -0.127 & -0.161 & -0.170 & -0.121 & -0.149 & $-0.205^{*}$ & -0.074 \\
\hline $\mathrm{C3}$ & -0.086 & -0.155 & -0.165 & -0.134 & -0.106 & -0.093 & -0.139 & -0.143 & -0.164 & -0.173 & $-0.212^{*}$ & -0.124 \\
\hline $\mathrm{Cz}$ & -0.077 & -0.128 & -0.135 & -0.126 & -0.150 & -0.151 & -0.177 & -0.131 & -0.187 & -0.179 & -0.193 & -0.111 \\
\hline $\mathrm{C4}$ & 0.007 & -0.081 & -0.155 & -0.145 & -0.048 & -0.089 & -0.181 & -0.157 & -0.124 & -0.164 & $-0.220^{*}$ & -0.143 \\
\hline$\overline{\mathrm{T} 4}$ & -0.050 & -0.146 & -0.195 & -0.116 & -0.022 & -0.075 & $-0.207^{*}$ & -0.146 & -0.060 & -0.121 & $-0.214^{*}$ & -0.038 \\
\hline T5 & -0.088 & -0.139 & -0.129 & -0.144 & -0.077 & -0.111 & -0.156 & -0.122 & -0.150 & -0.160 & -0.186 & -0.122 \\
\hline P3 & -0.089 & -0.136 & $-0.213^{*}$ & -0.172 & -0.008 & -0.066 & -0.146 & -0.158 & -0.142 & -0.140 & $-0.213^{*}$ & -0.150 \\
\hline$\overline{P z}$ & -0.116 & -0.137 & -0.167 & -0.135 & -0.089 & -0.093 & -0.197 & -0.168 & -0.173 & -0.146 & $-0.254^{*}$ & -0.173 \\
\hline P4 & -0.056 & -0.133 & -0.178 & -0.157 & -0.028 & -0.076 & -0.195 & -0.152 & -0.152 & -0.171 & -0.197 & -0.121 \\
\hline T6 & -0.084 & -0.161 & -0.103 & -0.105 & -0.133 & -0.137 & -0.191 & -0.128 & -0.164 & -0.142 & -0.150 & -0.094 \\
\hline 01 & -0.108 & -0.157 & -0.141 & -0.140 & -0.099 & -0.058 & -0.117 & -0.112 & -0.189 & -0.167 & -0.197 & -0.131 \\
\hline $\mathrm{Oz}$ & -0.075 & -0.199 & -0.164 & -0.140 & -0.141 & -0.147 & -0.161 & -0.126 & -0.169 & -0.158 & -0.160 & -0.091 \\
\hline$\overline{\mathrm{O} 2}$ & 0.012 & -0.029 & -0.151 & -0.035 & 0.009 & -0.019 & -0.149 & -0.092 & -0.113 & -0.149 & -0.198 & -0.117 \\
\hline
\end{tabular}

$P<0.01$ are printed in bold

${ }^{*} P<0.0028$

Since the correlation maps at alpha frequency reveal a distributed, in opposition to focal, relation with N1/N2 amplitudes and P2 latency, associated spatial patterns are investigated using PLS. The PLS analyses comprise 2 categories of calculation, namely resting alpha-oddball amplitude and resting alpha-oddball latency. We notice that for each of the 2 PLS computations, only 1 prominent singular value satisfies the 10 percent criterion, with respective contribution 95.0 percent and 91.7 percent for oddball amplitude and latency. The permutation tests show that the respective probabilities to have singular values greater than the largest singular value are 0 and 0.0016 . Concordant with the correlation maps, the saliencies associated with N1/N2 amplitudes as well as P2 latency are equipped with robust statistics, summarized in Table 3. It is interesting that for the two spatial patterns (from amplitudes and latencies of oddball ERPs) no regional specificity is noticed for all the

Table 3 The analyses of partial least squares on oddball ERP for resting EEG powers at alpha band

\begin{tabular}{lllllllll}
\hline \multicolumn{4}{c}{ Amplitude } & \multicolumn{4}{c}{ Latency } \\
\hline N1 & $\mathbf{P 2}$ & $\mathbf{N 2}$ & $\mathbf{P 3}$ & $\mathbf{N 1}$ & $\mathbf{P 2}$ & $\mathbf{N 2}$ & $\mathbf{P 3}$ \\
\hline Saliency & $\mathbf{0 . 6 6 5}$ & -0.189 & $\mathbf{0 . 6 6 7}$ & -0.276 & 0.325 & $\mathbf{0 . 9 0 2}$ & 0.271 & -0.087 \\
\hline$P$ value & $\mathbf{0 . 0 0 1}$ & 0.820 & $\mathbf{0 . 0 0 1}$ & 0.931 & 0.039 & $\mathbf{1 0 ^ { - 5 }}$ & 0.061 & 0.720 \\
\hline$P<0.01$ are printed in bold & & & & &
\end{tabular}

electrodes at alpha frequency, summarized in Table 4. The contents of Table 3 and 4 in fact can be viewed as the weighting factors for oddball ERPs and electrodes that contribute to the optimized variance-covariance structures after SVD, correspondent to the largest singular values for the relationship of oddball amplitude resting alpha and oddball latency - resting alpha. Together, the alpha oscillations that modulate N1/N2 amplitude and P2 latency reflect general characteristics of the brain, not confined to fronto-parietal network.

\section{Discussion}

The oddball paradigm is a cognitive surrogate in probing the capability of target detection, which demands attention allocation, stimulus evaluation and comparison, and has been widely applied in a variety of neuropsychiatric conditions. This study examines the hypothesis of whether the brain oscillation in the resting state, i.e. irrelevant to the active experiment, could predict the elicited oddball ERPs. Our design is different from that of event-related synchronization/desynchronization, which follows a triggering stimulus. Our analyses show that alpha power in the resting state is negatively correlated with the negativity of N1/N2 and the latency of P2. Without exception, the correlating trend (positive or negative) is consistent for all the significant qEEG indices in terms of each oddball ERPs component. The 
Table 4 The analytic results of partial least squares regarding the saliencies of electrodes at alpha frequency band for amplitudes and latencies of oddball ERP

\begin{tabular}{lllll}
\hline & Amplitude & $\boldsymbol{P}$ value & Latency & $\boldsymbol{P}$ value \\
\hline $\mathrm{F} 7$ & -3.494 & 0.0002 & -3.354 & 0.0004 \\
\hline $\mathrm{F} 3$ & -3.276 & 0.0005 & -3.507 & 0.0002 \\
\hline $\mathrm{Fz}$ & -3.278 & 0.0005 & -3.317 & 0.0005 \\
\hline $\mathrm{F} 4$ & -3.184 & 0.0007 & -3.483 & 0.0002 \\
\hline $\mathrm{F} 8$ & -3.309 & 0.0005 & -3.352 & 0.0004 \\
\hline $\mathrm{T} 3$ & -3.565 & 0.0002 & -3.697 & 0.0001 \\
\hline $\mathrm{C} 3$ & -3.047 & 0.0012 & -3.881 & 0.0001 \\
\hline $\mathrm{Cz}$ & -3.195 & 0.0007 & -3.925 & $<10^{-4}$ \\
\hline $\mathrm{C} 4$ & -3.607 & 0.0002 & -4.391 & $<10^{-4}$ \\
\hline $\mathrm{T} 4$ & -3.705 & 0.0001 & -4.249 & $<10^{-4}$ \\
\hline $\mathrm{T} 5$ & -3.305 & 0.0005 & -4.671 & $<10^{-4}$ \\
\hline $\mathrm{P} 3$ & -3.857 & 0.0001 & -3.942 & $<10^{-4}$ \\
\hline $\mathrm{Pz}$ & -3.707 & 0.0001 & -4.504 & $<10^{-4}$ \\
\hline $\mathrm{P} 4$ & -3.804 & 0.0001 & -3.927 & $<10^{-4}$ \\
\hline $\mathrm{T} 6$ & -2.893 & 0.0019 & -2.129 & 0.0166 \\
\hline $\mathrm{O} 1$ & -1.646 & 0.0499 & -3.334 & 0.0004 \\
\hline $\mathrm{Oz}$ & -3.131 & 0.0009 & -2.708 & 0.0034 \\
\hline $\mathrm{O} 2$ & -2.353 & 0.0093 & -3.940 & $<10^{-4}$ \\
\hline & & & &
\end{tabular}

demonstrated aggregated correlation patterns indicate that the interaction between the resting versus activation conditions possesses spectral specificity. The finding of resting alpha oscillation and $\mathrm{N} 1 / \mathrm{N} 2 / \mathrm{P} 2$ is concordant with previous literature addressing the contribution of alpha dynamics to the generation of ERPs [33,34]. We do not notice any significant correlation between resting qEEG and P3 latency/amplitude, though. Contradictory to our prediction, our multivariate analysis of PLS reveals no topographical preference, such as fronto-parietal network, for the neural-neural interactions. Instead, it seems a global property of the brain reflected in resting neurodynamics that predicts the earlier component of P300.

$\mathrm{N} 1$ and P2 have been associated with lower-level perceptual processing and mental speed, while N2 is relevant to short-term memory and influenced by stimulus novelty $[65,66]$. Our analyses show that the stronger the alpha power in the resting and relaxed state, the greater the magnitude of the negative peaks at $\mathrm{N} 1$ and $\mathrm{N} 2$ of oddball ERPs. Although alpha power has been associated with an arousal level that may influence N1/N2 [21,67], arousal may not be an appropriate interpretation in this study since the oddball ERPs were acquired in a widely awake status and was independent of the eye-closed resting condition. An alternative and more straightforward account is that the value of alpha power during eyes-closed relaxation represents the degree of automatic neural orchestration/synchronization. It may be the property of innate synchronization, not necessarily via arousal, that modulates the amplitude of $\mathrm{N} 1$ and $\mathrm{N} 2$ in target detection. However, the possibility that the participants were at similar arousal level in both experimental conditions (i.e. resting and oddball) cannot be completely excluded.

Stronger regional power at alpha is observed to shorten the P2 latency. As with the widely distributed alpha oscillations in predicting N1/N2 amplitudes, the significant correlations spread over most of the electrodes, again indicating that the relation of resting and activation conditions is substantiated by a "global" neural characteristic. This observation is further endorsed by the PLS computation. The oddball P2 was reported to be correlated with response time $[66,68,69]$, concordant with our observation at the latency dimension of P2. Although P2 was associated with mental speed, the scalp topography for P2 was similar in overt and covert responding conditions [70]. In addition, P2 was sensitive to task difficulty $[25,68]$. The psychological function of P2 may be pertinent to stimulus evaluation in the earlier processing stage rather than to the response production.

Even though all oddball ERPs components are relevant to the processing of the target, the components P2 and $\mathrm{N} 2$ have been regarded as different from P3. It was reported that the P2/N2 stage reflected automatic processing, whereas the P3 stage was capacity-limited, as suggested by the design manipulating task difficulty [71]. Coupled with our negative findings of P3, our results indicate that the neural characteristics carried by resting brain dynamics play a certain role in the earlier/ automatic stage of target detection, with the stronger synchronization in resting relaxation, the higher or faster evoked potentials in the automatic processing stage. Our discovery is conceptually analogous to other reports showing that the neural property in the resting state has a fair predictability about various behavioral phenotypes, such as the performance on several neuro-psychological tasks, as well as the manifestation of neuropsychiatric diseases [38-46]. Recent studies have further suggested a correspondence between structural and functional connectivity at a resting state [47-49]. Together, the bridge between the resting alpha oscillation and the earlier components of oddball ERPs could be mediated by the hardwire organization of neural architecture.

Our finding at alpha frequency is intriguing since alpha oscillation has been related to a wide variety of cognitive processes. For example, alpha frequency was significantly correlated with the speed of information processing [72] and alpha power change has been observed in long-term memory, semantic processing and attention deployment [73-75]. Regional and long-range connectivity change at alpha frequency has also been noticed in executive functioning [76]. Synchronization 
of EEG alpha used to be regarded as an index of "idling" state since alpha power has been reported to be negatively correlated with brain activity, as reflected by metabolic and hemodynamic indices via positron emission tomography and functional magnetic resonance imaging, respectively [77-79]. However, recent reports observed increased alpha in creative thinking and/or in a state with higher internal processing demands [80,81]. Klimesch et al. proposed a theory of inhibition-timing that alpha synchronization is "functional" and reflects active, top-down, inhibitory control processes [82]. The spreading of cortical activation (such as the dynamics of topography of ERP) may be controlled by timely decreased inhibition, indicated by de-synchronization of alpha power, at the regions associated with particular mental processing. In other words, the titrated reduction of alpha control may shape the ERP complex. Our findings endorse and extend Klimesch et al.'s hypothesis in that the degree of innate (resting) alpha synchronization/desynchronization may also influence cortico-electrical activity in activation state (such as oddball ERPs).

It has been suggested that ERP may be explained by superimposed oscillatory components, notably delta and theta components in oddball ERPs [83-85]. The proposition and observation have led to the theory of "oscillatory neural assemblies" to account for ERP generation [86]. Nevertheless, concordant with this study, pre-stimulus alpha activity has been noticed to modulate auditory oddball ERPs and visual ERPs $[87,88]$. Together with our findings and the inhibition-timing theory of alpha proposed by Klimesch et al. [82], there seem to be a crossspectral interaction between the resting or pre-stimulus alpha and delta/theta components of the elicited ERP. Furthermore, the pre-stimulus spectral activity may serve as a mediator between the EEG activities in resting condition and in activation condition. It is thus worthwhile for future studies to design a unified method framework and brain model to delineate the relationship of corticoelectrical characteristics between different mental states and across different spectrum. Although our results highlight a global pattern at alpha rhythm, Bonferroni correction of multiple comparisons may be too stringent to mask regional contribution. Alternative statistical strategy such as False Discovery Rate can be considered in future studies to clarify the roles of specific brain regions in the generation of oddball ERPs.

It is noteworthy that our findings do not provide an exclusive account for the oddball ERPs. In fact, there are plenty of psychological and biological factors that modulate the oddball ERPs profiles. For example, it was suggested that N1 amplitude was accentuated in response to enhanced cortical arousal and increased top-down cognitive effort [21-23], and earlier component N1/P2 was affected by bi-aural competition [24]. Evidence suggested that N1 and P2 were different, with increased task difficulty imposing no effect on N1, but decreasing the amplitude of P2 [25]. N2/P3, the later component of oddball ERPs, was affected by several contextual factors in addition to attention engagement, such as perceived emotion, affective arousal, background music and even personality [17,89-91]. Both early and late oddball ERPs were influenced by practicing meditation [89]. The pharmacological perturbation of oddball ERPs is complicated. It was reported that captopril increased the N1-P2 component, vasopressin enhanced $\mathrm{N} 2$, and caffeine increased the amplitude of P3 [26-28], while ethanol affected both early and late ERP components of oddball ERPs [29,30]. Oddball ERPs was also differentiated by genetic factors, such as polymorphisms of serotonin transporter, nicotine receptor and apolipoprotein $[23,31,32]$. Whether the psychological, contextual, pharmacological and genetic modulators of oddball ERPs are mediated by the change in alpha oscillation is an important issue demanding further research to clarify.

Several studies have demonstrated that the baseline features immediately preceding stimulus onset can predict subsequent neural response or neuropsychological performance [92-94]. It should not be confused that the resting "baseline" in our design is not immediately preceding to the experimental event and has nothing to do with the trial-by-trial variation. Unlike the studies exploring N1/N2/P2 dipole sources of oddball ERPs, our positive findings are not restricted to fronto-parietal network or superior temporal plane [95-99]. Nevertheless, this study delineates a cortico-electrical linkage between brain informatics in resting and activation states. Our results complement the understanding of various modulators of oddball ERPs and imply that the resting alpha dynamics is one of the candidates that affect the earlier components (N1/P2/N2) [17,23,26-32,89-91]. Whether the resting dynamics also explain the earlier stages of ERPs of other experimental conditions is an issue of interesting theoretical implication.

\section{Conclusion}

There are plenty biological and psychological modulators of oddball ERPs. The neuromatrix in the resting state has been reported to carry abundant information as an endo-phenotype. This study relates the brain dynamics in resting state to those in activation state of target detection. Our analyses suggest that the neural characteristics carried by resting brain modulate the earlier/automatic stage of target detection. The modulatory effects show spectral specificity at alpha band but no topographical preference. 


\section{Acknowledgements}

This work was supported by grant DOH94-NNB-1035 from the Department of Health, Taiwan, ROC and grant KS92-015 from the Kai-Suan Psychiatric Hospital-Kaohsiung. We are grateful to Mr. James Ascencio who helped prepare this manuscript.

\section{Author details}

'Laureate Institute for Brain Research, Tulsa, Oklahoma, USA. ${ }^{2}$ College of Medicine, Chang Gung University, Taoyuan County, Taiwan. ${ }^{3} Y$ Yu's Psychiatric Clinic, Kaohsiung, Taiwan. ${ }^{4}$ Kai-Suan Psychiatric Hospital, Kaohsiung, Taiwan. ${ }^{5}$ Department of Psychiatry, E-DA Hospital, Kaohsiung County, Taiwan. ${ }^{6}$ Department of Occupational Therapy, I-Shou University, Kaohsiung County, Taiwan.

\section{Authors' contributions}

All the authors contributed to the conception and design of this project. Authors TJC and YWYY designed the study and refined the protocol. Author TWL managed the literature search and statistical analysis, and wrote the first draft of the manuscript. Authors TJC, YWYY and HCW executed the experiment protocol and undertook the EEG data collecting procedure, subject evaluation and quality control. All authors contributed to and have approved the final manuscript.

\section{Competing interests}

The authors declare that they have no competing interests.

Received: 27 July 2011 Accepted: 24 November 2011 Published: 24 November 2011

\section{References}

1. Parsons OA, Sinha R, Williams HL: Relationships between neuropsychological test performance and event-related potentials in alcoholic and nonalcoholic samples. Alcohol Clin Exp Res 1990, 14:746-755.

2. Attias J, Bleich A, Furman V, Zinger Y: Event-related potentials in posttraumatic stress disorder of combat origin. Biol Psychiatry 1996, 40:373-381.

3. Begleiter H, Porjesz B, Rawlings R, Eckardt M: Auditory recovery function and P3 in boys at high risk for alcoholism. Alcohol 1987, 4:315-321.

4. Yu YW, Chen TJ, Chen MC, Tsai SJ, Lee TW: Effect of age and global function score on schizophrenic p300 characteristics. Neuropsychobiology 2005, 51:45-52.

5. Barry RJ, Clarke AR, McCarthy R, Selikowitz M, Brown CR, Heaven PC: Eventrelated potentials in adults with Attention-Deficit/Hyperactivity Disorder: an investigation using an inter-modal auditory/visual oddball task. Int J Psychophysiol 2009, 71:124-131.

6. Bruder GE, Kroppmann CJ, Kayser J, Stewart JW, McGrath PJ, Tenke CE: Reduced brain responses to novel sounds in depression: P3 findings in a novelty oddball task. Psychiatry Res 2009, 170:218-223.

7. Filipovic SR, Drulovic J, Stojsavljevic N, Levic Z: The effects of high-dose intravenous methylprednisolone on event-related potentials in patients with multiple sclerosis. J Neurol Sci 1997, 152:147-153.

8. Gilmore CS, Clementz BA, Buckley PF: Stimulus sequence affects schizophrenia-normal differences in event processing during an auditory oddball task. Brain Res Cogn Brain Res 2005, 24:215-227.

9. Sachs G, Anderer P, Margreiter N, Semlitsch H, Saletu B, Katschnig H: P300 event-related potentials and cognitive function in social phobia. Psychiatry Res 2004, 131:249-261.

10. Geisler MW, Polich J: P300 is unaffected by glucose increase. Biol Psychol 1994, 37:235-245.

11. Alexander JE, Polich J, Bloom FE, Bauer LO, Kuperman S, Rohrbaugh J, Morzorati S, O'Connor SJ, Porjesz B, Begleiter H: P300 from an auditory oddball task: inter-laboratory consistency. Int J Psychophysiol 1994, 17:35-46.

12. Walhovd KB, Fjell AM: One-year test-retest reliability of auditory ERPs in young and old adults. Int J Psychophysiol 2002, 46:29-40.

13. Näätänen R: Event-related potentials and automatic information processing Hillsdale, New Jersey: Lawrence Erlbaum Associates; 1992.

14. Näätänen $\mathrm{R}$, Picton $\mathrm{T}$ : The $\mathrm{N} 1$ wave of the human electric and magnetic response to sound: a review and an analysis of the component structure. Psychophysiology 1987, 24:375-425.
15. Folstein JR, Van Petten C: Influence of cognitive control and mismatch on the N2 component of the ERP: a review. Psychophysiology 2008, 45:152-170.

16. Donchin $\mathrm{E}$, Coles MGH: Is the $\mathrm{P} 300$ component a manifestation of context updating? Behav Brain Sci 1988, 11:357-374.

17. Caldwell GN, Riby LM: The effects of music exposure and own genre preference on conscious and unconscious cognitive processes: a pilot ERP study. Conscious Cogn 2007, 16:992-996.

18. Campanella S, Gaspard C, Debatisse D, Bruyer R, Crommelinck M, Guerit JM: Discrimination of emotional facial expressions in a visual oddball task: an ERP study. Biol Psychol 2002, 59:171-186.

19. Harver A, Squires NK, Bloch-Salisbury E, Katkin ES: Event-related potentials to airway occlusion in young and old subjects. Psychophysiology 1995, 32:121-129.

20. Martin BA, Sigal A, Kurtzberg D, Stapells DR: The effects of decreased audibility produced by high-pass noise masking on cortical eventrelated potentials to speech sounds/ba/and/da. J Acoust Soc Am 1997, 101:1585-1599.

21. Brown CR, Clarke AR, Barry RJ, McCarthy R, Selikowitz M, Magee C: Eventrelated potentials in attention-deficit/hyperactivity disorder of the predominantly inattentive type: an investigation of EEG-defined subtypes. Int J Psychophysiol 2005, 58:94-107.

22. Campbell KB, Colrain IM: Event-related potential measures of the inhibition of information processing: II. The sleep onset period. Int $\mathrm{J}$ Psychophysiol 2002, 46:197-214.

23. Enge S, Fleischhauer M, Lesch KP, Strobel A: On the role of serotonin and effort in voluntary attention: Evidence of genetic variation in N1 modulation. Behav Brain Res 2010.

24. Carpenter M, De Chicchis AR, Cranford JL, Hymel MR: Electrophysiologic correlates of attention versus stimulus competition in young male and female listeners. J Am Acad Audiol 2001, 12:142-149.

25. Cranford JL, Rothermel AK, Walker L, Stuart A, Elangovan S: Effects of discrimination task difficulty on $\mathrm{N} 1$ and $\mathrm{P} 2$ components of late auditory evoked potential. J Am Acad Audiol 2004, 15:456-461.

26. Dixit A, Vaney N, Tandon OP: Evaluation of cognitive brain functions in caffeine users: a P3 evoked potential study. Indian J Physiol Pharmacol 2006, 50:175-180.

27. Derad I, Pietrowsky R, Dodt C, Fehm HL, Born J: Enhanced psychophysiological signs of attention after angiotensin-converting enzyme inhibition by captopril. Psychophysiology 1996, 33:295-301.

28. Dodt C, Pietrowsky R, Sewing A, Zabel A, Fehm HL, Born J: Effects of vasopressin on event-related potential indicators of cognitive stimulus processing in young and old humans. J Gerontol 1994, 49:M183-188.

29. Campbell KB, Lowick BM: Ethanol and event-related potentials: the influence of distractor stimuli. Alcohol 1987, 4:257-263.

30. Colrain IM, Taylor J, McLean S, Buttery R, Wise G, Montgomery I: Dose dependent effects of alcohol on visual evoked potentials. Psychopharmacology (Berl) 1993, 112:383-388.

31. Espeseth $T$, Rootwelt $H$, Reinvang I: Apolipoprotein E modulates auditory event-related potentials in healthy aging. Neurosci Lett 2009, 459:91-95.

32. Espeseth $T$, Endestad T, Rootwelt $H$, Reinvang I: Nicotine receptor gene CHRNA4 modulates early event-related potentials in auditory and visual oddball target detection tasks. Neuroscience 2007, 147:974-985.

33. Makeig S, Westerfield M, Jung TP, Enghoff S, Townsend J, Courchesne E, Sejnowski TJ: Dynamic brain sources of visual evoked responses. Science 2002, 295:690-694

34. Gruber WR, Klimesch W, Sauseng P, Doppelmayr M: Alpha phase synchronization predicts $\mathrm{P} 1$ and N1 latency and amplitude size. Cereb Cortex 2005, 15:371-377.

35. Barry RJ, de Pascalis V, Hodder D, Clarke AR, Johnstone SJ: Preferred EEG brain states at stimulus onset in a fixed interstimulus interval auditory oddball task, and their effects on ERP components. Int J Psychophysiol 2003, 47:187-198.

36. Anokhin AP, van Baal GC, van Beijsterveldt CE, de Geus EJ, Grant J, Boomsma DI: Genetic correlation between the P300 event-related brain potential and the EEG power spectrum. Behav Genet 2001, 31:545-554.

37. Gilmore CS, Malone SM, lacono WG: Brain electrophysiological endophenotypes for externalizing psychopathology: a multivariate approach. Behav Genet 2010, 40:186-200. 
38. Mulert C, Juckel G, Brunnmeier M, Karch S, Leicht G, Mergl R, Moller HJ, Hegerl U, Pogarell O: Prediction of treatment response in major depression: integration of concepts. J Affect Disord 2007, 98:215-225.

39. Jelic V, Kowalski J: Evidence-based evaluation of diagnostic accuracy of resting EEG in dementia and mild cognitive impairment. Clin EEG Neurosci 2009, 40:129-142.

40. Neuper C, Grabner RH, Fink A, Neubauer AC: Long-term stability and consistency of EEG event-related (de-)synchronization across different cognitive tasks. Clin Neurophysiol 2005, 116:1681-1694.

41. Hermens DF, Soei EX, Clarke SD, Kohn MR, Gordon E, Williams LM: Resting EEG theta activity predicts cognitive performance in attention-deficit hyperactivity disorder. Pediatr Neurol 2005, 32:248-256.

42. Hoptman MJ, Davidson RJ: Baseline EEG asymmetries and performance on neuropsychological tasks. Neuropsychologia 1998, 36:1343-1353.

43. Coben LA, Chi D, Snyder AZ, Storandt M: Replication of a study of frequency analysis of the resting awake EEG in mild probable Alzheimer's disease. Electroencephalogr Clin Neurophysiol 1990, 75:148-154

44. Babiloni C, Cassetta E, Binetti G, Tombini M, Del Percio C, Ferreri F, Ferri R, Frisoni G, Lanuzza B, Nobili F, et al: Resting EEG sources correlate with attentional span in mild cognitive impairment and Alzheimer's disease. Eur J Neurosci 2007, 25:3742-3757.

45. Ramos-Loyo J, Gonzalez-Garrido AA, Amezcua C, Guevara MA: Relationship between resting alpha activity and the ERPs obtained during a highly demanding selective attention task. Int J Psychophysiol 2004, 54:251-262.

46. Beschoner P, Richter S, Lo H, Sim EJ, Baron K, Osterfeld N, Horn AB, Viviani R: Baseline brain perfusion and working memory capacity: a neuroimaging study. Neuroreport 2008, 19:1803-1807.

47. Teipel SJ, Bokde AL, Meindl T, Amaro E Jr, Soldner J, Reiser MF, Herpertz SC, Moller $\mathrm{HJ}$, Hampel $\mathrm{H}$ : White matter microstructure underlying default mode network connectivity in the human brain. Neuroimage 2010, 49:2021-2032

48. Greicius MD, Supekar K, Menon V, Dougherty RF: Resting-state functional connectivity reflects structural connectivity in the default mode network. Cereb Cortex 2009, 19:72-78.

49. Skudlarski P, Jagannathan K, Calhoun VD, Hampson M, Skudlarska BA, Pearlson G: Measuring brain connectivity: diffusion tensor imaging validates resting state temporal correlations. Neuroimage 2008, 43:554-561.

50. Romani A, Bergamaschi R, Callieco R, Cosi V: Prestimulus EEG influence on late ERP components. Boll Soc Ital Biol Sper 1991, 67:77-82.

51. Anticevic A, Repovs G, Shulman GL, Barch DM: When less is more: TPJ and default network deactivation during encoding predicts working memory performance. Neuroimage 2010, 49:2638-2648.

52. Sambataro F, Murty VP, Callicott JH, Tan HY, Das S, Weinberger DR, Mattay VS: Age-related alterations in default mode network: impact on working memory performance. Neurobiol Aging 2010, 31:839-852.

53. Charlton RA, Barrick TR, Lawes IN, Markus HS, Morris RG: White matter pathways associated with working memory in normal aging. Cortex 2010, 46:474-489.

54. Hirayasu Y, Samura M, Ohta H, Ogura C: Sex effects on rate of change of P300 latency with age. Clin Neurophysiol 2000, 111:187-194.

55. Anderer P, Semlitsch HV, Saletu B: Multichannel auditory event-related brain potentials: effects of normal aging on the scalp distribution of $\mathrm{N} 1$, P2, N2 and P300 latencies and amplitudes. Electroencephalogr Clin Neurophysiol 1996, 99:458-472.

56. Friedman D, Simpson G, Hamberger M: Age-related changes in scalp topography to novel and target stimuli. Psychophysiology 1993, 30:383-396.

57. Golgeli A, Suer C, Ozesmi C, Dolu N, Ascioglu M, Sahin O: The effect of sex differences on event-related potentials in young adults. Int $J$ Neurosci 1999, 99:69-77.

58. Duffy FH, Lyer G, Surwillo WW: Clinical electroencephalography and topographical brain mapping New York: Springer-Verlag; 1989

59. Lin CH, Yu YW, Chen TJ, Tsa SJ, Hong CJ: Association analysis for dopamine D2 receptor Taq1 polymorphism with P300 event-related potential for normal young females. Psychiatr Genet 2001, 11:165-168.

60. Fingelkurts AA, Rytsala H, Suominen K, Isometsa E, Kahkonen S: Impaired functional connectivity at EEG alpha and theta frequency bands in major depression. Hum Brain Mapp 2007, 28:247-261.
61. Mclntosh AR, Bookstein FL, Haxby JV, Grady CL: Spatial pattern analysis of functional brain images using partial least squares. Neuroimage 1996, 3:143-157.

62. McIntosh AR, Lobaugh NJ: Partial least squares analysis of neuroimaging data: applications and advances. Neuroimage 2004, 23(Suppl 1):S250-263.

63. Caplan JB, Glaholt MG: The roles of EEG oscillations in learning relational information. Neuroimage 2007, 38:604-616.

64. Efron B, Tibshirani R: Bootstrap methods for standard errors, confidence intervals, and other measures of statistical accuracy. Statistical Science 1986, 1:54-77.

65. Ferrari V, Bradley MM, Codispoti M, Lang PJ: Detecting novelty and significance. J Cogn Neurosci 2010, 22:404-411.

66. Verma NP, Nichols CD, Greiffenstein MF, Singh RP, Hurst-Gordon D: Waves earlier than P3 are more informative in putative subcortical dementias: a study with mapping and neuropsychological techniques. Brain Topogr 1989, 1:183-191.

67. Semlitsch HV, Anderer P, Saletu B: Acute effects of the anxiolytics suriclone and alprazolam on cognitive information processing utilizing topographic mapping of event-related brain potentials (P300) in healthy subjects. Eur J Clin Pharmacol 1995, 49:183-191.

68. Kim KH, Kim JH, Yoon J, Jung KY: Influence of task difficulty on the features of event-related potential during visual oddball task. Neurosci Lett 2008, 445:179-183.

69. Tong Y, Melara RD, Rao A: P2 enhancement from auditory discrimination training is associated with improved reaction times. Brain Res 2009, 1297:80-88.

70. Potts GF: An ERP index of task relevance evaluation of visual stimuli. Brain Cogn 2004, 56:5-13.

71. Kenemans JL, Verbaten MN, Melis CJ, Slangen JL: Visual stimulus change and the orienting reaction: event-related potential evidence for a twostage process. Biol Psychol 1992, 33:97-114.

72. Klimesch W, Doppelmayr M, Schimke H, Pachinger T: Alpha frequency, reaction time, and the speed of processing information. $J$ Clin Neurophysiol 1996, 13:511-518.

73. Klimesch W: Memory processes, brain oscillations and EEG synchronization. Int J Psychophysiol 1996, 24:61-100.

74. Klimesch W, Schimke H, Doppelmayr M, Ripper B, Schwaiger J, Pfurtscheller G: Event-related desynchronization (ERD) and the Dm effect: does alpha desynchronization during encoding predict later recall performance? Int J Psychophysiol 1996, 24:47-60.

75. Klimesch W, Doppelmayr M, Russegger H, Pachinger T: Theta band power in the human scalp EEG and the encoding of new information. Neuroreport 1996, 7:1235-1240.

76. Sauseng P, Klimesch W, Schabus M, Doppelmayr M: Fronto-parietal EEG coherence in theta and upper alpha reflect central executive functions of working memory. Int J Psychophysiol 2005, 57:97-103.

77. Danos P, Guich S, Abel L, Buchsbaum MS: Eeg alpha rhythm and glucose metabolic rate in the thalamus in schizophrenia. Neuropsychobiology 2001, 43:265-272.

78. Sadato N, Nakamura S, Oohashi T, Nishina E, Fuwamoto Y, Waki A, Yonekura Y: Neural networks for generation and suppression of alpha rhythm: a PET study. Neuroreport 1998, 9:893-897.

79. Laufs H, Kleinschmidt A, Beyerle A, Eger E, Salek-Haddadi A, Preibisch C, Krakow K: EEG-correlated fMRI of human alpha activity. Neuroimage 2003, 19:1463-1476.

80. Benedek $M$, Bergner $S$, Konen T, Fink A, Neubauer AC: EEG alpha synchronization is related to top-down processing in convergent and divergent thinking. Neuropsychologia 2011.

81. Fink A, Schwab D, Papousek I: Sensitivity of EEG upper alpha activity to cognitive and affective creativity interventions. Int J Psychophysiol 2011.

82. Klimesch W, Sauseng P, HansImayr S: EEG alpha oscillations: the inhibition-timing hypothesis. Brain Res Rev 2007, 53:63-88.

83. Stampfer $\mathrm{HG}$, Basar E: Does frequency analysis lead to better understanding of human event related potentials. Int I Neurosci 1985, 26:181-196.

84. Demiralp T, Ademoglu A, Istefanopulos Y, Basar-Eroglu C, Basar E: Wavelet analysis of oddball P300. Int J Psychophysiol 2001, 39:221-227.

85. Basar-Eroglu C, Demiralp T, Schurmann M, Basar E: Topological distribution of oddball 'P300' responses. Int J Psychophysiol 2001, 39:213-220. 
86. Karakas S, Erzengin OU, Basar E: The genesis of human event-related responses explained through the theory of oscillatory neural assemblies. Neurosci Lett 2000, 285:45-48.

87. Brandt ME, Jansen BH, Carbonari JP: Pre-stimulus spectral EEG patterns and the visual evoked response. Electroencephalogr Clin Neurophysiol 1991, 80:16-20.

88. Price GW: The effect of pre-stimulus alpha activity on the auditory P300 paradigm: a prospective study. Brain Topogr 1997, 9:169-176.

89. Cahn BR, Polich J: Meditation (Vipassana) and the P3a event-related brain potential. Int J Psychophysiol 2009, 72:51-60.

90. Eriksen HR, Nordby H, Olff M, Ursin H: Effects of psychological defense on processing of neutral stimuli indicated by event-related potentials (ERPs). Scand J Psychol 2000, 41:263-267.

91. Rozenkrants B, Polich J: Affective ERP processing in a visual oddball task: arousal, valence, and gender. Clin Neurophysiol 2008, 119:2260-2265.

92. Boly M, Balteau E, Schnakers C, Degueldre C, Moonen G, Luxen A, Phillips C, Peigneux $P$, Maquet $P$, Laureys $S$ : Baseline brain activity fluctuations predict somatosensory perception in humans. Proc Natl Acad Sci USA 2007, 104:12187-12192.

93. Gladwin TE, Lindsen JP, de Jong R: Pre-stimulus EEG effects related to response speed, task switching and upcoming response hand. Biol Psychol 2006, 72:15-34.

94. Guderian S, Schott BH, Richardson-Klavehn A, Duzel E: Medial temporal theta state before an event predicts episodic encoding success in humans. Proc Natl Acad Sci USA 2009, 106:5365-5370.

95. Tarkka IM, Stokic DS, Basile LF, Papanicolaou AC: Electric source localization of the auditory P300 agrees with magnetic source localization. Electroencephalogr Clin Neurophysiol 1995, 96:538-545.

96. Giard MH, Perrin F, Echallier JF, Thevenet M, Froment JC, Pernier J: Dissociation of temporal and frontal components in the human auditory N1 wave: a scalp current density and dipole model analysis. Electroencephalogr Clin Neurophysiol 1994, 92:238-252.

97. Mulert C, Jager L, Schmitt R, Bussfeld P, Pogarell O, Moller HJ, Juckel G, Hegerl U: Integration of $\mathrm{FMRI}$ and simultaneous EEG: towards a comprehensive understanding of localization and time-course of brain activity in target detection. Neuroimage 2004, 22:83-94.

98. Clarke JM, Halgren E, Chauvel P: Intracranial ERPs in humans during a lateralized visual oddball task: II. Temporal, parietal, and frontal recordings. Clin Neurophysiol 1999, 110:1226-1244.

99. Verleger R, Heide W, Butt C, Kompf D: Reduction of P3b in patients with temporo-parietal lesions. Brain Res Cogn Brain Res 1994, 2:103-116.

doi:10.1186/1471-2202-12-121

Cite this article as: Lee et al:: Do resting brain dynamics predict oddball evoked-potential? BMC Neuroscience 2011 12:121.

\section{Submit your next manuscript to BioMed Central and take full advantage of:}

- Convenient online submission

- Thorough peer review

- No space constraints or color figure charges

- Immediate publication on acceptance

- Inclusion in PubMed, CAS, Scopus and Google Scholar

- Research which is freely available for redistribution

Submit your manuscript at www.biomedcentral.com/submit
Ciomed Central 